\title{
Patient - Service Provider Communication is a Key for Patients' Satisfaction in Emergency Department -Cairo University Hospitals - Egypt
}

\author{
Ghada W. Mohamed, Eman Taher
}

Department of Public Health, Faculty of Medicine, Cairo University, Egypt

Received March2015, accepted April2015

\section{Abstract}

The satisfaction profile of emergency care patients guides strategies for improving quality of pre-hospital and in-hospital care. Aim: Display resources and hospital bed utilization pattern 2009-2013 in Cairo University Hospital -Emergency Department, tracking pre-hospital events and delineate the perspectives of patients towards hospital services.

Methods: Setting: the study was conducted in. Design Cairo University Hospital Emergency Department sampling: cross-sectional study that recruited 208 patients discharged from CUH-ED in year 2013. Data sources: the accessible service statistics of CUH-ED 2009 - 2013, and structured interview guide for recoding patient's data. Data analysis tested the association of pre-hospital and in-hospital care with overall patient satisfaction at time of discharge from CUH-ED.

Results:In CUH-ED 2013,nurse: bed ratio was 1: 7.6 per shift; bed occupancy rate $84 \%$ and average length of hospital stay was 4 days and in-hospital mortality $1.2 \%$. There were insignificant difference between satisfied and unsatisfied patients by socio-demographic background, and configuration of pre-hospital events and condition at discharge (improved/deteriorated). Satisfaction from physician performance was detected in $76.3 \%$ of patients, while satisfaction from nurse performance was elicited in $51.8 \%$. About $69.7 \%$ of patients expressed their satisfaction from patient-provider communication $(\mathrm{p}<0.001 \mathrm{OR}=205 \mathrm{CI}=27-$ 1560).

Conclusion: Patient-provider communication in CUH-ED is appreciated by patients to be a key for quality services for in-hospital emergency care.

Keywords :Patient satisfaction, configuration of pre-hospital events, patient-provider communication.

*corresponding author, Email, emantaher100@gmail.com (Eman Taher Elsayed)

\section{Introduction}

The mission of Emergency Department (ED) in Hospitals is to function as "an exclusive hospital department in which highly specialized care is delivered to the acutely ill and injured with consideration for safety net care to be provided to the vulnerable and marginalized population." (1) Quality care in such departments is crucial for patient safety, favorable outcome of care, and reduced disease burden across different strata of the population. ${ }^{(2,3)}$ However, emergency care is one of the weakest parts of the health system in low and middle income countries due to maldistribution of trauma care centers, ${ }^{(4,5)}$ unsatisfactory infrastructure and 
routines, and lack of professional training of service providers. (6) A study conducted in Pakistan to evaluate emergency and trauma care showed that primary and secondary health care facilities have equipment less than $60 \%$ as included in WHO guidelines for emergency care versus more than $80 \%$ of all tertiary hospitals. The average score of physicians' knowledge about basic emergency care was $30 \%$ in the three health care levels. ${ }^{(7)}$

There is a controversy about the prehospital care for emergency cases (in the field of care, resuscitation and transport), as in-hospital care is governed by using specific emergency care guidelines. ${ }^{(8)}$ Proper pre-hospital care could reduce hospital admissions and save lives. ${ }^{(9,10)}$ However, in some developing countries, some study conducted to assessing the pre-hospital emergency events according to WHO guidelines showed lack of medical supply and improper ambulance staff training. ${ }^{(11)}$

The situation is different in developed countries. A systematic review of trauma system concluded that: In Germany there is a comprehensive trauma system that include four subsystems: prevention of trauma, especially traffic accidents and firearm-related injuries, in-hospital treatment team of different specialties, healthcare covering patients from injury to rehabilitation, and strengthened trauma and injury research to deal with various questions of trauma care. ${ }^{(12)}$ Egypt has an wellestablished "injury surveillance system" where reporting of cases using a standardized formula have to be completed by health units and hospitals. Electronic information system (EIS) allows the flow of information from districts to directorates to central levels. Annual reports on injuries reflect the pattern of injury cases as mortality and morbidity indicators at national and governorate levels. Mortality indicators include death rate from injury/violence to total population, the ratio of death rate from injuries among males and females, death rates by cause of injury to total population and death rates by cause of injury for different age groups. Morbidity indicators include hospital admission rate by cause of injury and for different age groups. ${ }^{(13)}$ However the "injury report form" does not include information about pre-hospital configuration of events as accident time, contacted health facilities before admission, transport services, condition at discharge from the hospital and patients' satisfaction.

Patients' satisfaction surveys provide an important source of health system information for improving quality of care strategies. ${ }^{(14,15)}$ The study for 86 patients with traumatic brain injury was testing a tool for measurement of measuring patients' satisfaction using self-administered questionnaire form that included 30 questions on hospital care. ${ }^{(16)}$ However, such study did not consider pre-hospital events. Pre-testpost-test study in a tertiary hospital trauma care department concluded that improved quality of care provided by a specialized trauma team succeeded in reducing the significant effect of delays in hospital transit and lack of pre-hospital trauma care. Both mortality and complication rates showed marked reduction. ${ }^{(17)}$

For identification of Cairo University Hospital -Emergency care (CUH-EC) in-hospital services that guide to key strategies for quality care, it is necessary to have information that consider "injury- health care- home cycle" to be articulated with perception 
of the patients (satisfaction/nonsatisfaction) from in -hospital services. Studies in Egypt based on the trauma registry in tertiary hospitals provided basic demographic data, injury details as burden of severe injuries, quality indicators as Length of stay in Emergency department (ED), and injury arrival delay. Those studies did not configure pre-hospital events and did not include any indicators that measure performance of service providers and patients' perspectives. ${ }^{(18,}$ 19)

\section{Objectives}

Display hospital bed utilization pattern 2009-2013 in Cairo University Hospital -Emergency department (CUH-ED), tracking pre-hospital events and delineate the perspectives of inpatients' perspectives towards hospital services (satisfied/dissatisfied).

Methods: Setting: The study was conducted in the CUH-ED. It is a tertiary care ED and the largest in Egypt. It is located at the middle of Egypt's capital and has the capacity of 53 beds and an average admissions per year of 4800 patients (age $\geq 15$ years; cases less than 15 years are managed in the Pediatrics ED).

Design: The study composed of two stages: a retrospective stage for hospital resources and utilization pattern throughout 2009- 2013, and cross-sectional stage that included all cases discharged from CUH-ED throughout two weeks in the year 2013.

Sampling: For the cross-sectional stage, the sample size was calculated using OpenEpi available at http://www.openepi.com using the following figures: average population size per month (time permitted from the CUH-ED for completion of data collection) $=400$ inpatients, anticipated percent of satisfied inpatients $=50$, alpha error $=5 \%$, power $=80 \%$, confidence level $=95 \%$, and design effect $=1$. Sample size calculation yielded 197 participants.

Data sources/tools: 1 - the accessible service statistics for CUH-ED 20092013 which cover all admissions in the age group 15 years and more 2structured interview guide for recoding patient's data at time of discharge of patients from CUH-ED. The structured interview guidelines were adopted from MOHP- Injury Surveillance form. (13) Patients' satisfaction was measured using patients' satisfaction questionnaire developed by Prasad et al, $2013^{(16)}$. It was measured by asking questions about different domains on a scale of excellent to poor. Their level of satisfaction was recorded by selecting responses ranging from poor $=1$, fair $=2$, good $=3$, very $\operatorname{good}=4$ and excellent $=5$. Each domain was scored from excellent to poor, with higher scores indicating higher levels of patients' satisfaction. The questionnaire was pilot tested on 30 patients to get the final form.

Data analysis: For each numeric variable, the normality of distribution was preliminarily assessed by the Kolmogorov-Smirnov test. If normally distributed, variables were generally expressed as mean $( \pm \mathrm{SD})$, otherwise variables were expressed as median $\left(25^{\text {th }}\right.$ quartile, $75^{\text {th }}$ quartile $) . \quad$ All qualitative data were presented as frequency and percentages. The relation of each variable to outcome categories was separately tested by the chi-square test for categorical variables. The outcome variable (patients' satisfaction) was dichotomized into satisfied if the patients rated satisfaction as good, very good, or excellent, and not satisfied if they rated satisfaction as average or 
poor. For all variables, odds ratio estimates with corresponding 95\% confidence interval $(\mathrm{CI})$ are presented. All p-values below 0.05 were considered significant. Data analysis was conducted using SPSS v.15.

Ethical considerations: the concept paper of the study and structured interview guidelines were approved by Public Health Department Research Ethics committee and CUH-ED staff. An official approval was obtained from CUH-Statistics Department to access the required service statistics. Participants provided informed verbal consents after explaining the study objectives to them and assuring them the confidentiality of their responses (the filled interview questionnaires are kept in closets and not accessed except by the researchers and only for the research purposed) study ethical considerations were in accordance with the Declaration of Helsinki.

Limitations of the study: Due to civil instability in years 2011-2012, and overflow of cases to CUH-ED, Statistical Department did not accept publication of imprecise data for those reference years. Therefore, the data that will be analyzed cover the period before January 25 revolution (2011 2009 and 2010 ) and after revolution (2013)

\section{Results}

Table (1) illustrates the CUH-ED hospital bed utilization pattern for three years 2009, 2010 and 2013. As depicted from the table ED capacity/volume of beds was constant throughout the reference years. There were three physicians across the 24 hours. The nurse: bed ratio was 1: 7.6 per shift. The bed occupancy rate (BOR) was kept at a level more than $80 \%$. It was highest in year 2010 and lowest in 2013. Also in 2013, bed turnover rate and In-hospital mortality
$(1.2 \%)$ were lowest compared to other reference years.

Figure (1) displays the profile of CUHED patients included in the study. It is obvious The majority of cases $(82 \%)$ were in the productive age group. Males formed $70 \%$ of cases. Those had history of school enrolment formed $56 \%$ of cases. The working for cash cases were $59 \%$ and $41 \%$ were not working for cash.

Table (2) demonstrates sociodemographic background of CUH-ED patients included in the study in relation to their overall satisfaction from in-hospital services. About $79 \%$ of both productive $(15-<60$ years) and non- productive age groups $(60+$ years) expressed overall satisfaction from CUH-ED services. About $83 \%$ of female cases expressed satisfaction versus $81 \%$ of male cases with statistically insignificant difference ( $\mathrm{p}=0.8$ OR $=0.9$ CI $0.4 ; 2.0)$. About $83 \%$ of non-educated cases expressed satisfaction from CUH-ED services versus $80 \%$ of educated cases with a statistically insignificant difference $(\mathrm{p}=0.6 \quad$ OR $=1.2 \quad$ CI $0.6 ; 2.4)$. According to work status; $85 \%$ of those not working for cash expressed satisfaction from CUH-ED services versus $79.5 \%$ of those working for cash with statistically insignificant difference $(p=0.3$ OR=1.4 CI 0.7; 3.0 ).

Figure (2) describes the injury and preCUH/ED admission events among the studied cases. Seventy percent of the cases exposed to acute condition or accidental injuries within the active hours of the day $(8 \mathrm{am}-11 \mathrm{pm})$. The events of emergency condition occurred in a place outside the catchment area of CUH for $90 \%$ of cases. More than half of the cases (54\%) came directly to CUH (either from home or injury place); $28 \%$ passed through one health facility and 
$18 \%$ passed through more than one facility before $\mathrm{CUH}$ admission. Consequently, the total referred cases from health facilities were $46 \%$ of all studied cases. The role of ambulance transportation was marginal as $83 \%$ came to CUH by their own methods of transportation.

Table (3) describes the trip of injured cases from time of health problem occurrence to hospital admission and their overall satisfaction from CUHED. Those who had their accident time within active hours of the day (8 am $11 \mathrm{pm})$ reported overall satisfaction $82.6 \%$ compared to $76.6 \%$ of cases who had their accident time within inactive hours of the day (11 pm -8 am) with a statistically insignificant difference $(\mathrm{p}=0.4$ OR $=0.7$ CI 0.3 ; 1.6). Out of $182(87.5 \%)$ cases came from areas outside the CUH catchment area, about $80 \%$ expressed general satisfaction versus $88.5 \%$ of cases came from the $\mathrm{CUH}$ catchment area with a statistically insignificant difference $(\mathrm{p}=0.2$ OR $=0.5$ CI 0.1 ; 2.1). There were tendency for cases passed through more than one facility before admission to CUH to be satisfied with CUH services (84.2\%) compared to those came directly from home or passed through one health facility $(81.2 \%) \quad$ statistically insignificant difference between the two groups $(\mathrm{p}=0.7 \mathrm{OR}=1.2$ CI 0.4 ; 3.2). Almost all cases that passed through 1 or more health facility were referred to $\mathrm{CUH}$ (46.6\% of the total cases). Out of the referred cases, $83.6 \%$ expressed satisfaction from CUH services compared to $80.2 \%$ of those bypassed any facility and went directly to $\mathrm{CUH}$, but there was no statistically insignificant difference between the two groups $(\mathrm{p}=0.5 \mathrm{OR}=$ 0.8 CI $0.4 ; 1.7)$. Out of those who came to $\mathrm{CUH}$ without an ambulance $(82.6 \%), 83.1 \%$ reported satisfaction versus $75 \%$ who used ambulance transportation with statistically insignificant difference between the two groups $(\mathrm{p}=0.2 \mathrm{OR}=1.6$ CI 0.7 ; $3.8)$.

Figure (3) shows the perspectives of CUH-ED patients towards specific items of health care. Patients appreciated the performance of physicians as $78 \%$ of them expressed their satisfaction. Patient-provider communication was figured out as satisfactory by $70 \%$ of the patients. The response of service provider to patients

(Provider-Patient communication) was stated as satisfactory by $68 \%$ of cases. Nurses' performance was satisfactory to $52 \%$ of the patients and hospital amenities satisfied less than half of the cases $(48 \%)$.

Table (4) delineates the association between perception of specific items of care and overall patients' satisfaction from CUH-ED. Additionally, the table provides information about outcome of care, as $74 \%$ reported improvement of their condition at time of discharge from the hospital. Among those who revealed their improved condition, $86.7 \%$ expressed their overall satisfaction from CUH-ED versus $87.1 \%$ of those reported deterioration of their condition, but the difference in the two proportions of cases was statistically insignificant $(\mathrm{p}=0.8 \mathrm{OR}=$ $0.96 \mathrm{CI}=0.29 ; 3.2$ ).

Demonstrating specific health care items in relation to percent of respondents indicated that only 169 $(81.3 \%)$ were eligible to express perception towards physician performance and 166 (79.8\%) were eligible to express perception towards nurses' performance. On the other hand $100 \%$ of the cases responded to patient- provider communication and provider-patient communication. 
Accordingly, the cases were either exposed to services from both ED physicians and nurses, or physicians only or nurses.

Among cases who received services from physicians, $76.3 \%$ were satisfied. This satisfaction from physicians' performance was associated with a statistically significantly high proportion of patients' overall satisfaction $(99.2 \%) \quad(\mathrm{p}=0.00 \quad \mathrm{OR}=$ 213 CI 26.9 ; 1689.1). Among cases who received services from nurses, $51.8 \%$ were satisfied. This satisfaction from the nurses' performance was associated with a statistically significantly high proportion of patients' overall satisfaction $(96.5 \%)$ $(\mathrm{p}=0.00 \mathrm{OR}=11.2$ CI $3.2 ; 38.9)$. As well, the table shows also that patients' active contribution in the discussion of his health condition with the service provider was satisfactory for $69.7 \%$ of patients. This level of satisfaction from communication was associated with a significantly high proportion of cases to be satisfied from overall CUH-ED services.

\section{Discussion}

The current study is a health services research concerned with a special category of patients that passed through critical steps to be admitted to a tertiary hospital within an unstable civil environment involving every place in Egypt after January $25^{\text {th }}$ 2011. Such situation was reflected on the Management Information System within the hospital as non-accessible statistical information about the critical two critical years of civil instability and violence (2011- 2012). Therefore, the presented service statistics data provide norm/usual performance of CUH-ED in a stable civil/political environment. The displayed performance of the CUH-ED throughout three years $(2009,2010$, 2013) showed fluctuation in BOR $(87 \%, 116 \%$ and $84 \%)$. The highest rate in 2010 was due to increases in average hospital stay days (5 days/patient) rather than the increase in number of admissions. The average length of hospital stay (LOS) was $(3,5$ and 4 days), and BTR (96,88, 81). The demonstrated figures in CUH-ED reflected inefficiency in the hospital bed utilization. According to Komindr et al., $2014^{(20)}$ the standard derived from different countries' emergency departments indicated that the average LOS ranged from 12. 9 to 20.5 hours and BTR 1.6 patients /bed per day to 0.9 patient /bed per day.

In 2010, the recorded high BOR $(116 \%)$ reflects high caseload at certain period of time within the year in addition to longer LOS (5 days). High caseload could be due to lack of hospital beds in the ED for admitted cases, shortage in nursing staff, major emergency cases, increase number of patients, the wide scope of needed hospital services, delays in services provided by ancillary departments, limited flexibility to increase the number of beds due to limited space, difficulty in the transfer process for home care that lead to longer hospital stay. ${ }^{(21)}$

Such situation of high caseload could result in unsatisfactory performance. Weissman et al., 2007 (22) demonstrated that hospital work at over capacity of more than $100 \%$ BOR increases the risk of occurrence of adverse events. A $0.1 \%$ increase in patient -to-nurse ratio led to a $28 \%$ increase in adverse events rate that negatively influences patient safety. Drummond 2002 (23) added the increase cost due to longer hospital stay, especially for cases with elective 
surgery. (24) Additionally, high stressillness in an overcrowded environment increases violence against service providers as verbal abuse and Therefore, Drummond 2002 (23) suggested the ED should be flexible during the changing civil environment to increase the capacity of ED beds, expand supply of qualified nurses, trained emergency physicians, and improve informatics to advocate for more care to ED, fast- track programs to emergency cases that need short time response for needed services and improve ambulance service provision.

Despite that, emergency departments could provide specific emergency care services (medications and procedures) or surgical interventions; CUH-ED service statistics do not include indicators about surgical cases. Nagaraja et al., $2014^{(25)}$ mentioned indicators used for acute surgical units as derived from systematic reviews and meta-analysis: incidence of complications, reduction in conversion rate to open surgery, reduction in night time operations.

Despite that trauma registries are key sources for defining the burden of injury and developing quality improvement processes, (26) they have several limitations. Egypt, as many, countries have a registry-based statistics for emergency cases at the national level by MOHP (13) and local level. ${ }^{(27)}$ According to MOHP annual report 2009, fall was the first cause of injury (20\%), followed by an assault / fight (19\%), road/traffic accidents (13\%), sharp objects (12\%), animal bite $(12 \%)$, needle stick injury $(8 \%)$ and poisoning $(6 \%)$. The information in this report under-estimate the problem, as it is institutional-based for cases who used ambulance transportation (as reported in the injury report form) ${ }^{(13) .}$ Local level study in
Alexandria 2000-2010 revealed that road accident was the first leading cause of mortality and $70 \%$ of injury related deaths occurred in the age group $15-<60$ years. Men were more at risk than women except in burns. High injury rates were calculated for poor and remote districts. Summer months showed the highest seasonal index for each type of and all injuries combined. The study, based on the trauma registry in tertiary hospitals, provided basic demographic data, injury details such as burden of severe injuries, and quality indicators such as LOS in ED and injury arrival delay. It did not include any indicators that measure performance of service providers or patients' perspectives. (18) The study was conducted in Assuit/Egypt and included all hospitalized cases which were 19869 in 2002 and become 32699in 2009 with an estimated increase by $65 \%$ over 8 years. For the total 8 years cases 213.835 , the admitted cases were 68018, and two thirds were treated without hospital admission. Despite that falls was the first cause of injury (44\%), followed by traffic accidents (31\%), traffic accident was the first leading cause of death, followed by falls. There was no information about changes in bed volume in trauma departments in Assuit tertiary hospitals. ${ }^{(19)}$ Thus, such registries do not go beyond descriptive statistics, and do not provide keys for improvement in health care for emergency cases. However, special clinical studies in ED used Audit Filters (AF). AF is a mechanism for improving quality of care. It is specific clinical processes or outcomes of care that when occur represent unfavorable deviations from an established norm. Such devotion is a key for action to promote the quality of care. (28) The study conducted in a German University Hospital was concerned with the relation between cost of care, 
pre-hospital care and type of inhospital services delivered four for cases. Findings showed that, the most costly components were intensive care (60\% of the total cost) followed by procedures in the operating room (24\%). Factors that were significantly associated with the costs of acute care hospitalization were outcome, severity of injury, pattern of injury, blood volume replaced, length of mechanical ventilation, and the number of operations. Patient's age, CNS state, mechanism of injury, pre-hospital care and time between accident and hospital admission revealed no effect. ${ }^{(29)}$

The current study is concerned with the emergency cycle (pre-hospital circumstances-in-hospital care and discharge from hospital). The concept of studying this cycle is highly acknowledged by another study (30) which tested is testing for the key for quality of emergency care that yields high emergency cases' satisfaction from hospital care. Professionals and organizations can use quality measurement tools to identify problem areas. However, measuring patients' experiences is a key to improving care. It is important to identify the key aspects of care that are relevant to the patients' ' perception of care. Valid measures contain multiple care domains that serve as constructs in patients' conception of quality. These components vary across different patient populations. Other studies followed patients up from admission to discharge and after returning back to him to test-and retest perspectives. ${ }^{(30)}$ The current study reflects the patient's experience throughout the period from the injury occurrence till discharge from hospital. This reflects a patientcentered, community-health system interaction and its impact on patients' satisfaction from hospital services. Our findings indirectly reflected the shortcomings in pre-hospital care services which are matched with other studies. ${ }^{(11,4)}$ The indicators reflecting a shortage in injury care during the preadmission period to CUH-ED where: about $90 \%$ of cases came from areas away from the CUH catchment area, inadequate referral system as $53.4 \%$ came directly to the hospital and bypassed the primary and secondary levels of care, and about $83 \%$ of cases were deprived of first aid services that could be provided during transportation by ambulance facilities. There are driving factors that make people go directly to a tertiary care hospital. Kangovil et al., 2013 (21) claimed that the contribution of PHCambulatory services in the ED are minimal, especially cases of lowsocioeconomic class who prefer hospital care. People perceive hospital$\mathrm{ED}$ as less expensive, more accessible and higher quality care than ambulatory care. Razzak et al., 2001 (31) in a Pakistani study revealed minimal role of ambulance transportation, where $53 \%$ of cases go to hospital by taxi and $21 \%$ by private car. Specific reasons for not using ambulance were not sick enough (34\%), slow response of the ambulance services $(17 \%)$ or not knowing how to find an ambulance (8\%). Such situation of shortage in pre-hospital services could result in admission of minor conditions at the hospital due to better access, trust in the technical quality of service and providers. ${ }^{(32)}$ The current study demonstrated that females formed $30 \%$ of the studied cases. Our study findings coincide with the gender distribution of emergency cases at the national level (29\% females). (13) However, other studies considered gender issue playing a role in male versus female access to trauma care. In a retrospective population-based study of 26,861 severely injured cases, $35 \%$ of cases were females. Significant 
Small proportion of females compared to males received trauma care ( $49 \%$ vs. $62 \%)$. Emergency service personnel were less likely to transport females from the field to trauma center compared with males. ${ }^{(33)}$

The hypothesis emphasized by the study is that providing quality care in CUH-ED up to the level of achieving overall patients' overall satisfaction help patients overcome defects in prehospital care services. Such hypothesis was affirmed by the lack of significant association between patients' overall satisfaction level and socioeconomic background, and pre-hospital circumstances, and condition at discharge from CUH-ED. Such concept was affirmed by Hashmi et al., 2013. ${ }^{(17)}$ in a pre-test-post-test study in a tertiary hospital trauma care department. Hashmi concluded that improved quality of care provided by specialized trauma team succeeded in reducing the significant effect of delays in hospital transit and lack of pre-hospital trauma care; both mortality and complication rates showed marked reduction. ${ }^{(17)}$ However, a study used selfadministered questionnaire with a $13 \%$ response rate demonstrated different parameters of patient experience of care as a key for the quality of emergency services. Those reported high score of satisfaction were elderly people and those who had surgical procedures. The unsatisfied (low score) were the young, no surgery, and had complications. ${ }^{(34)}$

Patients' satisfaction is an important tool in assessment of quality of care in hospitals. Studies have concluded that the care givers' good proper communication with the patients are the most important measures for patients' satisfaction in the emergency an general wards ${ }^{(35,36)}$
The current study highlighted the role of physicians and nurses in technical performance as a cause of satisfaction from CUH-ED. As regards to nursing performance, this study demonstrated that a significant relation between patients' satisfaction and nurse performance. This finding is supported by Azizi-fini et al., $2012{ }^{\text {(37) who }}$ reported a significant direct correlation was observed between the scores of "nurses' caring behaviors" and “patients' satisfaction" $(P<0.001, \mathrm{r}=$ 0.57). Physician- patient communication during history taking or discussing about treatment plan is an important factor in patients' satisfaction, and it is considered a cornerstone in establishing a trusting physician-patient relationship, It also increases the quality of clinical services by physicians. ${ }^{(38)}$

The background knowledge that derived classes to go to this tertiary care hospital was the good reputation of CUH staff. A specification for Patient -Provider communication as the major factor associated with overall satisfaction from CUH-ED ( $\mathrm{p}=00 \mathrm{OR}$ $=205 \mathrm{CI}=27-1560)$ could guide researchers to in-depth analysis to identify items within this component of care to develop a valid and reliable tool for measurement, monitoring and evaluation of the quality of care in emergency departments. A similar finding was reported by Narenjiha et al., $2012^{(38)}$ They found that although patients' satisfaction was low (50\%), patients were mainly satisfied with training and answering their questions by doctors. In another study done by Clever et al., $2008^{(39)}$ to investigate the effect of doctor- patient communication on patients' satisfaction, the median rating for all of the behaviors was "very good." Only $33 \%$ of patients rated their attending 
physicians' communication behaviors as "excellent"; $12 \%$ gave ratings that corresponded to "fair" or "poor"

More detailed provider-patient communication items could be an element of training with specific standards/guidelines after matching them with the culture, demography, and injury status of cases. A controversy existed regarding satisfaction from the hospital environment and amenities which scored lowest for a patients' satisfaction index in a study carried out in out-patients departments in South Korea. ${ }^{(40)}$ Correspondingly, A similar result was reported in a study conducted at five hospitals served under healthcare system. (41) Furthermore, in 2012 Arshad et al. reported that the majhor dissatisfaction in an out-patient department was due to the long waiting time and overcrowded registration. ${ }^{(42)}$ In contrast, a study carried out in five different hospitals in Scotland found that physical comfort had the highest satisfaction rate compared to other core dimensions: information, coordination of care and emotional support. ${ }^{(43)}$

\section{Acknowledgement}

The authors would like to thank all the CUH-ED health team and the patients that participated and contributed to the completion and success of this work

\section{References}

1) Hwang U, Richardson LD, Sonuyi TO, and Morrison RS. The effect of emergency department crowding on the management of pain in older adults with hip fracture. Journal of the American Geriatric Society 2006;54(2): 270-275

2) Hirshon JM, and Skog A. A call to arms: support for emergency care isn't making the grade. National
Health policy Conference 2014 Avialable at http://healthaffairs.org/blog/2014/01 /16/a-call-to-arms-support-foremergency-care-isnt-making-thegrade/ accessed Feb 2015

3) Anderson PD, Suter RE, Mulligan T, Bodiwala G, Razzak JA, Mock C, International Federation for Emergency Medicine (IFEM) Task Force on Access and Availability of Emergency Care. World Health Assembly Resolution 60.22 and its importance as a health care policy tool for improving emergency care access and availability globally. Ann Emerg Med. 2012 Jul; 60(1):35-44.e3.

4) Gomez D, Haas B, Doumouras AG, Zagorski B, Ray J, Rubenfeld G, McLellan BA, Boyes DM, and Nathens AB. A population-based analysis of the discrepancy between potential and realized access to trauma center care. Ann Surg. 2013 Jan ;257(1):160-5.

5) Ciesla DJ, Pracht EE, Cha JY, and Langland-Orban BJ. Geographic distribution of severely injured patients: implications for trauma system development. Trauma Acute Care Surg. 2012 Sep; 73(3):618-24.

6) Baker T, Lugazia E, Eriksen J, Mwafongo $\mathrm{V}$, Irestedt $\mathrm{L}$, and Konrad d. Emergency and critical care services in Tanzania: a survey of ten hospital. BMC health services research 2013;13( 140):1-9

7) Razzak JA, Baqir SM, Khan UR, Heller D, Bhatti J, and Hyder AA. Emergency and trauma care in Pakistan: a cross-sectional study of healthcare levels. Emerg Med J. 2015 Mar; 32(3):207-13. 
8) Blackwell T, Kellam JF, and Thomason M. Trauma care systems in the United States. Injury. 2003 Sep; 34(9):735-9.

9) Spaite DW, Tse DJ, Valenzuela TD, Criss EA, Meislin HW, Mahoney M, and Ross J. The impact of injury severity and prehospital procedures on scene time in victims of major trauma. Ann Emerg Med. 1991 Dec; 20(12):1299-305.

10) Mock CN, Tiska M, AduAmpofo M, and Boakye G. Improvements in prehospital trauma care in an African country with no formal emergency medical services. J Trauma. 2002 Jul; 53(1):90-7.

11) Bhatt JA, Waseem $H$, and Razzak, JA. Availability and quality of prehospital care on pakistani interurban roads. Ann Adv Automot Med. 2013 Sep; 57: 257-264.

12) Sturm JA , Pape HC, and Dienstknecht $\mathbf{T}$. Trauma care in Germany: an inclusive system . Clin Orthop Relat Res. 2013 Sep; 471(9):2912-23.

13) WHO. injury surveillance a tool for decision making. Annual injury surveillance report Egypt. 2009 avialable at http://applications.emro.who.int/ dsaf/dsa1087.pdf Accessed december 2014

14) Hekkert KD, Cihagir S Kleefstra SM, Van Den Berg B, and KoolRB Patients' satisfaction Revisited: A Multilevel Approach. SocSci Med. 2009;69(1):68-75

15) Herrrera-Espineira C, Rodriguez del Aguila Mdel M, Rodriguez del Castillo M, Valdivia AF, Sanchez IR Relationship between Anxiety Level of Patients and their Satisfaction with different Aspects of Healthcare. Health Policy. 2009;89(1): 37-45

16) Prasad MV, Kumar SS, Agrawal A, and Mohan DR. Level of satisfaction in patients/attendants admitted with traumatic brain injury at an advanced ER/Casualty in a Tertiary Care Teaching Hospital. Journal of Hospital Administration. 2013; 2(2):89-96

17) Hashmi ZG , Haider AH, Zafar SN, Kisat M, Moosa A, Siddiqui F, Pardhan A, Latif A,and Zafar HJ Hospital-based trauma quality improvement initiatives: first step toward improving trauma outcomes in the developing world. Acute Care Surg. 2013 Jul; 75(1):60-8

18) Mehmood A, Razzak JA, Kabir S, MacKenzie EJ., and Hyder AA. Development and pilot implementation of a locally developed Trauma Registry: lessons learnt in a low-income country. BMC Emergency Medicine 2013; 13(4): 1-7

19) Mahran DG, Farouk OA, Qayed M, and Berraud AF. Hospitalized injuries and deaths in a trauma unit in upper Egypt. Int $\mathbf{J}$ Crit Illn Inj Sci. 2013 Oct; 3(4):235-40.

20) Komindr A, Baugh CW, Grossman SA, and Bohan JS. Key operational characteristics in emergency department observation units: a comparative study between sites in the United States and Asia. Int J Emerg Med. 2014 Feb 5;7(1):6.

21) Kangovil S, Barg FK, Carter T, Long JA, Shannon R, and Grande D. Understanding Why Patients Of Low Socioeconomic Status Prefer Hospitals Over Ambulatory Care. Health Aff. 2013; 32(7): 1196-1203 
22) WeissmanJS, Rothschild JM, Bendavid E, Sprivulis P, Cook F, Evans RS, Kaganova Y, Bender M, David-Kasdan J, Haug P, Lloyd J, Selbovitz LG, Murff HJ, and Bates DW. Hospital Workload and Adverse Events. Medical Care 2007 May;45 (5):448-455

23) Drummond AJ. .No room at the inn: overcrowding in Ontario's emergency departments. CJEM 2002;4(2):91-97

24) Rathlev NK, chessareJ, Olshaker J, Obendorfer D, Metha SD, etal. Time series analysis of variables associated with daily mean emergency department length of stay. Annuals of Emergency medicine 2007; 49 (3): 265-271

25) Nagaraja V, Eslick GD, and cox MR. The acute surgical unit model versus the traditional "on call" model: a systematic review and meta-analysis. World J Surg. 2014; 36(6): 1381-7

26) Stevens KA, Paruk F, Bachani AM, Wesson HH, Wekesa JM, Mburu J, Mwangi JM, Saidi H, and Hyder AA. Establishing hospital-based trauma registry systems: lessons from Kenya. Injury. 2013 Dec; 44 (4): 70-4.

27) Wahab MM. Incidence and patteren of injury- related mortality: a register- based followup study in Alexandria, Egypt ( 2000-2010). J Egypt Public Health Assoc. 2012 Apr; 87(1-2): 8-15

28) Evans C, Howes D, Pickett W, and Dagnone L. Audit filters for improving processes of care and clinical outcomes in trauma systems. Cochrane Database Syst Rev. 2009 Oct 7 ;(4):CD007590

29) Rösch M, Klose T, Leidl R, Gebhard F, Kinzl L, and Ebinger T. Cost analysis of the treatment of patients with multiple trauma. Unfallchirurg. 2000 Aug; 103(8):632-9.
30) Bobrovitz N, santana M, Kline T, Kortbeek J, and Stelfox HT. Prospective cohort study protocol to evaluate the validity and reliability of the Quality of Trauma Care Patient-Reported Experience Measure (QTAC-PREM). BMC Health Services Research 2013;13(98):1-8

31) Razzak JA, Cone DC, and Rehmani R. Emergency medical services and cultural determinants of an emergency in Karachi, Pakistan. Prehosp Emerg Care. 2001 Jul-Sep; 5(3):312-6.

32) McCarthy M. Poor people view hospitals as providing better access, care, and social support BMJ 2013; 347. available at http://www.bmj.com/content/347/b mj.f4556 Accessed January 2015

33) Gomez D, Haas B, de Mestral C, Sharma S, Hsiao M, Zagorski B, Rubenfeld G, Ray J, and Nathens AB. Gender-associated differences in access to trauma center care: A population-based analysis. Surgery. 2012 Aug; 152(2):179-85.

34) Rogers F, Horst M, To T, Rogers A, Edavettal M, Wu D, Anderson $\mathbf{J}$, Lee J, Osler T, and Brosey LJ. Trauma Acute Care Surg. Factors associated with patients' satisfaction scores for physician care in trauma patients 2013 Jul;75(1):110-4; discussion 114-5.

35) Goldwag R, Berg A, Yuval D, Benbassat J. Predictors of patient dissatisfaction with emergency care. Isr Med Assoc J. 2002;4(8):603- 6.

36) Boudreaux ED, O'Hea EL. Patients' satisfaction in the Emergency Department: a review of the literature and implications for practice.J Emerg Med. 2004;26(1):13-26 
37) Azizi-Fini I, Mousavi MS, Mazroui-Sabdani A, AdibHajbaghery M. Correlation Between Nurses' Caring Behaviors and Patients' Satisfaction. Nurs Midwifery Stud. 2012:1(1): 36-40.

38) Narenjiha $M$, Haghighat $S$, Bahaddor H, Shajari J, Jameie SB. The Importance of Physicians' Communication Skills on Patients' Satisfaction.Thrita J Med Sci. 2012;1(2): 57-61.

39) Clever SL, Jin L, Levinson W, and Meltzer DO. Does DoctorPatient communication affect patients' satisfaction with hospital care? Results of an analysis with a novel instrumental variable. HSR: Health Services Research 2008, 43(5) October;1505-1519

40) Kui-Son C, Hanjoon L, Chankon $\mathbf{K}$, and Sunhee $\mathbf{L}$. The service quality dimensions and patients' satisfaction relationships in South
Korea: comparisons across gender, age and types of service. Journal of Services Marketing 2005, 19(3); $140-149$

41) Koichiro O, Brian W, Kelly M F, Sarah B, Thomas E B and Claiborne D. Patients' satisfaction: Focusing on "Excellent", Journal of Healthcare Management 2009, 54(2);93-103

42) Andrabi SA, Hamid S, Rohul Jand Anjum F. Measuring patients' satisfaction: A cross sectional study to improve quality of care at a tertiary care hospital, Health line, 2012, 3(1); 59-62.

43) Jenkinson C, Coulter A, Bruster S, Richards N, and Chandola $T$. Patients' experience and satisfaction with Health Care: Results of a questionnaire study of specific aspects of care. Quality Safety Health Care 2003,11;335339 
Table (1): Hospital Bed Utilization Pattern in Cairo University Hospital- Emergency Department (CUH-ED) 2009-2013

\begin{tabular}{|l|c|c|c|c|c|c|}
\hline Year & Beds & Admissions & $\begin{array}{c}\text { Bed } \\
\text { Occupancy } \\
\text { Rate \% }\end{array}$ & $\begin{array}{c}\text { Bed Turnover } \\
\text { Rate(Patients) }\end{array}$ & $\begin{array}{c}\text { Average } \\
\text { Length of } \\
\text { Stay (Days) }\end{array}$ & $\begin{array}{c}\text { In- } \\
\text { Hospital } \\
\text { Mortality } \\
\text { \% }\end{array}$ \\
\hline 2009 & 53 & 5087 & $87 \%$ & 96 & 3 & $2 \%$ \\
\hline 2010 & 53 & 4836 & $116 \%$ & 88 & 5 & $2 \%$ \\
\hline 2013 & 53 & 4417 & $84 \%$ & 81 & 4 & $1.2 \%$ \\
\hline
\end{tabular}

Manpower resources include: Two professors, one resident/24 hours, 22 nurses distributed across 3 shifts, 15 security staff and 8 workers.

Table (2): Percent Distribution of Emergency Cases by Socio-Demographic background according to overall satisfaction from CUH-ED services

\begin{tabular}{|c|c|c|c|c|c|c|}
\hline \multirow[t]{2}{*}{$\begin{array}{l}\text { Socio-demographic } \\
\text { Background }\end{array}$} & \multicolumn{2}{|c|}{$\begin{array}{c}\text { Overall patients' } \\
\text { satisfaction } \\
\text { n. }(\%)\end{array}$} & \multirow[t]{3}{*}{$\begin{array}{c}\text { Total } \\
\mathrm{n}=\mathbf{2 0 8} \\
(\%)\end{array}$} & \multirow[t]{3}{*}{ OR } & \multirow[t]{3}{*}{ CI } & \multirow[t]{3}{*}{$\begin{array}{c}P \\
\text { Value }\end{array}$} \\
\hline & $\begin{array}{l}\text { Satisfied } \\
\text { n.=170(81.7) }\end{array}$ & $\begin{array}{l}\text { Unsatisfied } \\
\text { n.= 38(18.3) }\end{array}$ & & & & \\
\hline \multicolumn{3}{|l|}{ Age group(15-82 y) } & & & & \\
\hline $\begin{array}{l}15 \text { to }<60(81.7 \%) \\
60+(18.3 \%)\end{array}$ & $\begin{array}{l}30(78.9) \\
140(78.9)\end{array}$ & $\begin{array}{c}8(21.1) \\
30(17.6)\end{array}$ & $\begin{array}{c}38 \\
170\end{array}$ & 1.2 & $(0.52,2.98)$ & 0.62 \\
\hline \multicolumn{7}{|l|}{ Sex } \\
\hline $\begin{array}{l}\text { Male }(69.7 \%) \\
\text { Female }(30.3 \%)\end{array}$ & $\begin{array}{l}118(81.4) \\
52(82.5)\end{array}$ & $\begin{array}{l}27(18.6) \\
11(17.5) \\
\end{array}$ & $\begin{array}{c}145 \\
63 \\
\end{array}$ & 0.9 & $(0.42,2.00)$ & 0.84 \\
\hline \multicolumn{7}{|l|}{ Education } \\
\hline $\begin{array}{l}\text { Educated }(43.8 \%) \\
\text { Non-educated }(56.2 \%)\end{array}$ & $\begin{array}{l}73(80.2) \\
97(82.9) \\
\end{array}$ & $\begin{array}{l}18(19.8) \\
20(17.1)\end{array}$ & $\begin{array}{c}91 \\
117 \\
\end{array}$ & 1.2 & $(0.59,2.42)$ & 0.61 \\
\hline \multicolumn{7}{|l|}{ Work Status } \\
\hline $\begin{array}{l}\text { Working for cash }(58.7 \%) \\
\text { Not working for } \\
\text { cash }(41.3 \%)\end{array}$ & $\begin{array}{l}97(79.5) \\
73(84.9)\end{array}$ & $\begin{array}{l}25(20.5) \\
13(15.1)\end{array}$ & $\begin{array}{c}122 \\
86\end{array}$ & 1.4 & $(0.69,3.02)$ & 0.32 \\
\hline
\end{tabular}

${ }^{\text {a }} \mathrm{P}$ value is significant at levels $<0.05$. Chi squared test was used to detect significant difference 
Table (3) Percent of CUH-ED cases according to pre-admission circumstances and overall satisfaction from CUH-ED services

\begin{tabular}{|c|c|c|c|c|c|c|}
\hline & \multicolumn{2}{|c|}{$\begin{array}{c}\text { General patients' } \\
\text { satisfaction } \\
\text { n. }(\%)\end{array}$} & \multirow[t]{2}{*}{$\begin{array}{c}\text { Total } \\
\mathrm{n} .=208 \\
(\%)\end{array}$} & \multirow[t]{2}{*}{$\mathbf{O R}$} & \multirow[t]{3}{*}{$\mathbf{C I}$} & \multirow[t]{2}{*}{$\begin{array}{c}\mathbf{P} \\
\text { Value }^{\mathrm{a}}\end{array}$} \\
\hline & $\begin{array}{l}\text { Satisfied } \\
170(81.7)\end{array}$ & $\begin{array}{l}\text { Unsatisfied } \\
\text { 38(18.3) }\end{array}$ & & & & \\
\hline \multicolumn{6}{|l|}{ Accident time } & \\
\hline $\begin{array}{l}8 \text { am-before } 11 \text { pm } \\
\text { (early) }\end{array}$ & $119(82.6)$ & $25(17.4)$ & 144 & 0.7 & $(0.34,1.56)$ & 0.43 \\
\hline $\begin{array}{l}11 \mathrm{pm} \text { - before } 8 \mathrm{am} \\
\text { (late) }\end{array}$ & 49 (76.6) & $13(23.4)$ & 64 & & & \\
\hline \multicolumn{7}{|l|}{ Accident place } \\
\hline Same CUH district & $23(88.5)$ & $3(11.5)$ & 26 & 0.5 & $(0.10,2.13)$ & $0.25^{\mathrm{b}}$ \\
\hline Other ( & $145(79.7)$ & $37(20.3)$ & 182 & & & \\
\hline \multicolumn{7}{|c|}{ Contacted health facilities before admission } \\
\hline $0-1$ & $138(81.2)$ & $32(18.8)$ & 170 & 1.2 & $(0.47,3.21)$ & 0.67 \\
\hline$>1$ & $32(84.2)$ & $6(15.8)$ & 38 & & & \\
\hline \multicolumn{7}{|c|}{ Referral to CUH or came from home } \\
\hline Referred to CUH & $81(83.6)$ & $16(16.4)$ & 97 & 0.8 & $(0.39,1.64)$ & 0.55 \\
\hline From home & $89(80.2)$ & $22(19.8)$ & 111 & & & \\
\hline \multicolumn{7}{|l|}{ Transport to CUH } \\
\hline Ambulance & $27(75)$ & $9(25)$ & 36 & 1.6 & $(0.69,3.82)$ & 0.25 \\
\hline Others & $143(83.1)$ & $29(16.9)$ & 172 & & & \\
\hline
\end{tabular}

${ }^{a} \mathrm{P}$ value is significant at levels $<0.05$. Chi squared test was used to detect significant difference

${ }^{\mathrm{b}}$ Fisher's Exact test was used to detect significant difference 
Table (4): Percent of CUH-ED cases according to their perception to hospital services and overall satisfaction from CUH-ED services

\begin{tabular}{|c|c|c|c|c|c|c|}
\hline \multirow{2}{*}{$\begin{array}{l}\text { Hospital care Items } \\
\quad \text { (CUH-ED) }\end{array}$} & \multicolumn{2}{|c|}{$\begin{array}{c}\text { General patients' } \\
\text { satisfaction } \\
\text { n. }(\%)\end{array}$} & \multirow{2}{*}{$\begin{array}{l}\text { Total } \\
\text { n.=208 }\end{array}$} & \multirow{2}{*}{$\mathbf{O R}$} & \multirow[t]{2}{*}{ CI } & \multirow{2}{*}{$\begin{array}{c}\mathbf{P} \\
\text { Value }^{\mathrm{a}}\end{array}$} \\
\hline & $\begin{array}{l}\text { Satisfied } \\
170(81.7)\end{array}$ & $\begin{array}{l}\text { Unsatisfied } \\
38 \text { (18.3) }\end{array}$ & & & & \\
\hline \multicolumn{7}{|c|}{ Physicians' Performance ( $n=169$ ) } \\
\hline Satisfactory $(76.3 \%)$ & $128(99.2)$ & $1(0.8)$ & 129 & 213.3 & $(26.9-1689.1)$ & $<0.001$ \\
\hline Not Satisfactory $(23.6 \%)$ & $15(37.5)$ & $25(62.5)$ & 40 & & & \\
\hline \multicolumn{7}{|c|}{ Nurses' Performance( $n=166)$} \\
\hline Satisfactory $(51.8 \%)$ & $83(96.5)$ & $3(3.5)$ & 86 & 11.2 & $(3.2-38.9)$ & $<0.001$ \\
\hline Not Satisfactory $(48.2 \%)$ & $57(71.3)$ & $23(28.8)$ & 80 & & & \\
\hline \multicolumn{7}{|c|}{$\begin{array}{l}\text { Patient-Service provider communication: } \\
\text { the patient asks the providers freely }\end{array}$} \\
\hline Satisfactory $(69.7 \%)$ & $144(99.3)$ & $1(0.7)$ & 145 & 204.9 & $(26.9-1559.8)$ & $<0.001$ \\
\hline Not Satisfactory $(30.3 \%)$ & $26(41.3)$ & $37(58.7)$ & 63 & & & \\
\hline \multicolumn{7}{|c|}{$\begin{array}{l}\text { Service Provider-patient communication: } \\
\text { the provider responds to patients' inquiries }\end{array}$} \\
\hline Satisfactory $(68.3 \%)$ & $140(98.6)$ & $2(1.4)$ & 142 & 84 & $(19.2-368.1)$ & $<0001$ \\
\hline Not Satisfactory $(31.7 \%)$ & $30(48.5)$ & $36(51.5)$ & 66 & & & 0.001 \\
\hline \multicolumn{7}{|c|}{ Hospital Amenities ( $n=166$ ) } \\
\hline Satisfactory (48.2\%) & $76(95)$ & $4(5)$ & 80 & 6.5 & $(2.1-19.9)$ & $<0.001$ \\
\hline Not Satisfactory $(51.8 \%)$ & $64(74.4)$ & $22(25.6)$ & 86 & & & \\
\hline \multicolumn{7}{|c|}{ Condition at discharge from Hospital $(n=121)$} \\
\hline Improved $(74.4 \%)$ & $78(86.7)$ & $12(13.3)$ & 90 & 0.96 & $(0.3-3.2)$ & 08 \\
\hline Deteriorated $(25.6 \%)$ & $27(87.1)$ & $4(12.9)$ & 31 & & & 0.8 \\
\hline
\end{tabular}

${ }^{\text {a }} \mathrm{P}$ value is significant at levels $<0.05$. Chi squared test was used to detect significant difference 


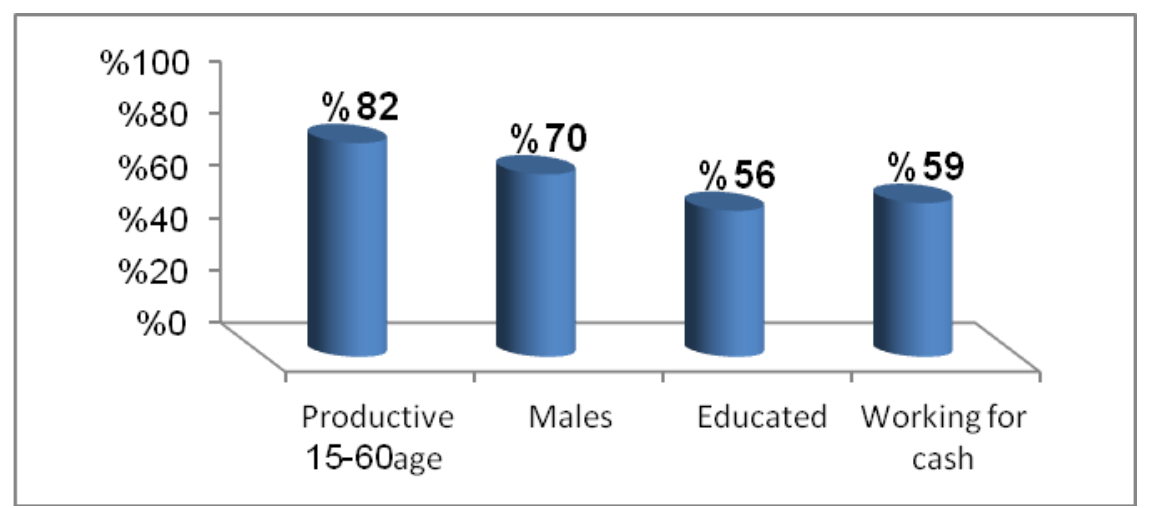

Figure (1) Percent of interviewed patients by selected socio-demographic parameters

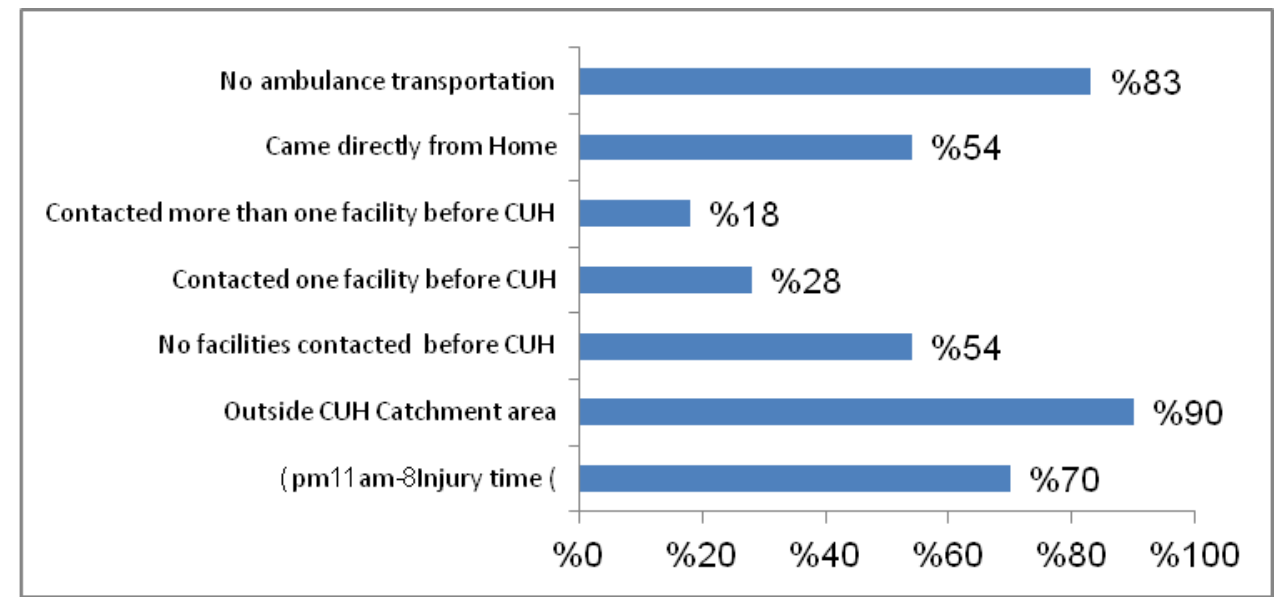

Figure (2) Percent of CUH-ED cases according to pre-hospital events

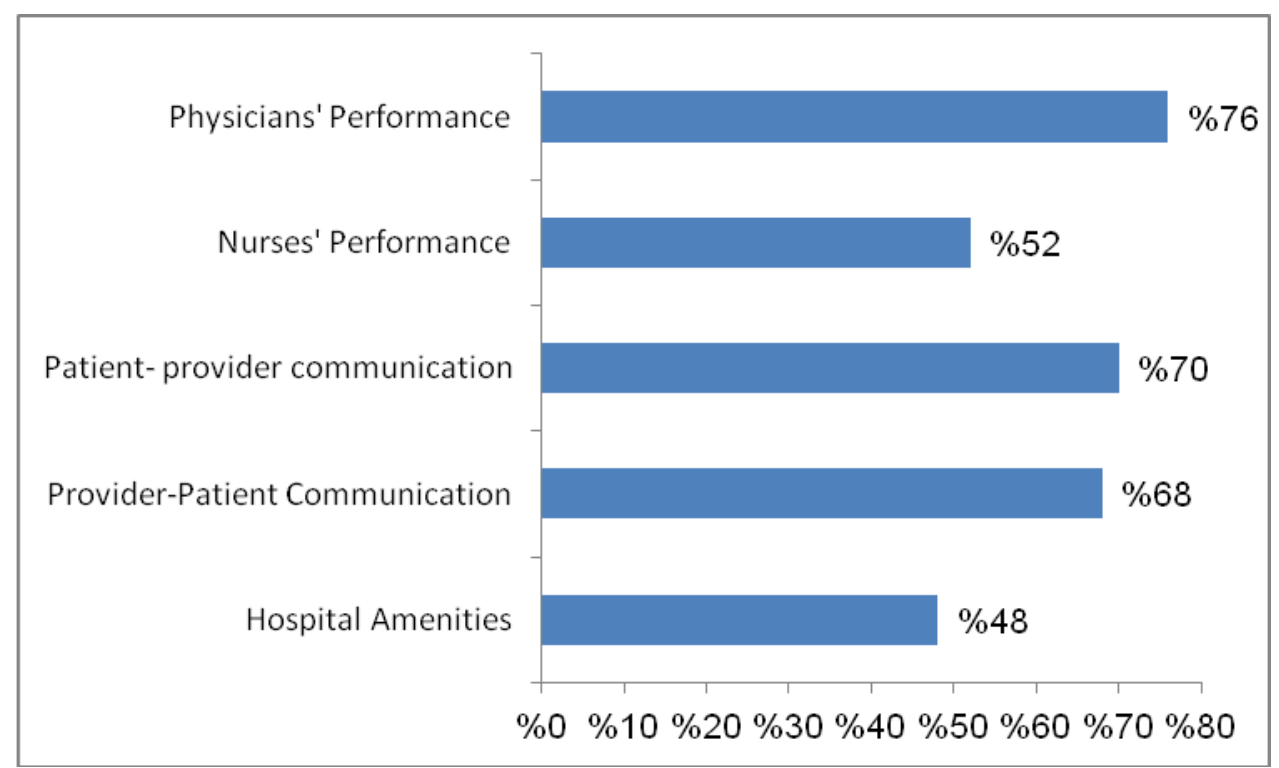

Figure (3) Percent of CUH-ED patients who expressed satisfaction from specific quality items of health services 